\title{
Narrativas del pasado y literatura infantil: continuidades y rupturas en los planteos críticos de Graciela Montes y Ana Maria Machado
} Laura Rafaela García ${ }^{1}$

Esta pudo haber sido la oportunidad, nuestra única oportunidad de enterarnos de dónde estaba Otroso, pero Rosita no estaba dispuesta a revelar nada, nunca más, a nadie. Se había envuelto sobre ella misma como una piedra, para golpear y castigar, no para abrirse y mostrar. Y aunque ella tuvo que notar que todos esperábamos que nos revelase el secreto, no nos dijo nunca nada.

Graciela Montes

El epígrafe de este trabajo pertenece a la novela Otroso: últimas noticias del mundo subterráneo, de Graciela Montes, publicada en 1991, que puede interpretarse como una forma soterrada de aludir a las prácticas militantes de los años setenta en Argentina, ya que da cuenta de una actividad secreta y colectiva que no puede revelarse en un marco de violencia creciente. La novela relata la experiencia de un grupo de adolescentes del barrio de Flores reunidos en torno a una publicación clandestina, además de realizar otras actividades que constituyen su mundo particular; en cierto momento estos jóvenes deben ocultarse para huir de las amenazas de la Patota que los persiguen por sus ideas y prácticas. Otroso es el nombre de ese mundo subterráneo que representa la experiencia del encierro, la persecución y la clandestinidad que podría ligarse a la práctica de los militantes durante la última dictadura argentina, al mismo tiempo para estos jóvenes ese mundo sirve de refugio y representa un modo de resistencia a las presiones del mundo real.

Varias metáforas giran en torno a este relato, en relación con las memorias del pasado es posible interpretar el texto como una forma ficcional de presentar una alternativa política durante la última dictadura. También, el texto presenta la metáfora del laberinto y el hilo de Ariadna para mostrar cómo se trama una historia y la vida de la protagonista que lleva ese nombre haciendo alusión a las formas del

\footnotetext{
${ }^{1}$ Doutora em literatura e pós-doutoranda no Instituto de Investigaciones sobre el Lenguaje y la Cultura (INVELEC) da Universidad Nacional de Tucumán (UNT), Tucumán, Argentina. E-mail: lau2garcia@hotmail.com
} 
discurso metaliterario. Por su parte, la autora le otorga a este texto un lugar particular en su poética como lo cuenta en una entrevista realizada por Ana Maria Machado. Al respecto Montes afirma:

Pero se seguía escribiendo (durante la época de la dictadura), aunque de manera un poco subterránea. En una novela que terminé poco después, Otroso, los protagonistas cavan un laberinto subterráneo para resistir la opresión de la Patota: creo que una sensación semejante teníamos entonces todos. Seguir escribiendo era una forma de resistencia. Menciono esta circunstancia porque creo que esa resistencia cultural compartida suscitó una solidaridad particular entre los escritores para niños, que desempeñó luego un papel cohesionante (Machado et al., 2005, p. 68, paréntesis y cursiva nuestra)

Estas palabras dan lugar a la experiencia personal de la autora durante la dictadura y muestran la escritura como una actividad que no se interrumpió sino que se mantuvo en forma solapada, después del impacto que provocó la prohibición de libros dentro del campo infantil argentino y las formas de la censura tanto en el ámbito cultural como en la vida social en general. Por nuestra parte, este relato integra la colección de lecturas de lo monstruoso (García, 2013a), que reúne una serie de narrativas ficcionales e interpelan al lector a partir de la situación o las escenas relatadas en el cruce con el contexto de publicación y la lógica de los textos agrupados. Esta colección fue planteada en otra instancia de investigación para contar el pasado reciente a los chicos². Entendemos junto con Rossana Nofal (2006) que la violencia política es comunicable por medio de la fantasía, por eso proponemos contar el pasado a partir de una serie de relatos que apelan a la ficción para referirse a las formas autoritarias del poder y, de este modo, contribuir a actualizar los itinerarios de transmisión.

Esta colección de lo monstruoso, en particular, toma como eje el concepto de fantasy literario (Jackson, 1986) y la idea de lo siniestro -de Freud- que deforma o vuelve ajeno el mundo familiar, dando lugar a una serie de situaciones narrativas que representan los efectos del

\footnotetext{
${ }^{2}$ Este artículo retoma y profundiza algunos puntos de la trayectoria de Graciela Montes planteados en mi tesis doctoral titulada Narrativas de la violencia política en la literatura infantil argentina: los trabajos de la memoria para contar la dictadura (1970-1990), dirigida por la dra. Rossana Nofal. En esa instancia se organizaron tres colecciones de lecturas que hacen posible narrar la violencia política desde los protocolos de la ficción de la literatura argentina para niños dentro del período estudiado.
} 
horror y las formas subjetivas del miedo como modos de aludir al pasado. Es importante considerar, por un lado, que Otroso junto con otros textos de la colección representan el desplazamiento del campo infantil por medio del ingreso de nuevas modulaciones de lo fantástico $\mathrm{y}$, por otro lado, que la producción de estos textos tiene como marco la emergencia pública en los medios masivos de comunicación de los testimonios de testigos y sobrevivientes de la dictadura que aportan a la reconstrucción de los hechos para la elaboración del informe de la Comisión Nacional sobre la Desaparición de Personas (CONADEP).

Consideramos que la literatura para niños es una zona literaria permeable a las realidades sociales que fue relegada a los márgenes del sistema literario, por eso proponemos reponer los hechos a partir de las memorias de los autores que con su actividad intelectual contribuyen entre otras cosas a ampliar las formas de representar la violencia política. En este trabajo revisaremos la experiencia del pasado a través de la mirada del campo principalmente en la literatura infantil argentina y ampliaremos el panorama hacia el caso de la literatura brasilera a través de la mirada de dos autoras representativas de ambos campos como son Graciela Montes y Ana Maria Machado. Indagaremos en los posicionamientos críticos de los años noventa en los que ambas autoras analizan el impacto de la dictadura en sus países y muestran su compromiso con la infancia. Además, el recorrido por sus posicionamientos nos permitirá darle continuidad a los estudios realizados en instancias anteriores de esta investigación y profundizar en algunas de las principales problemáticas que atraviesan la literatura para niños de ambos países en el contexto democrático de los años noventa.

En esta dirección es necesario retomar los postulados de Elizabeth Jelin (2002) sobre el campo de las memorias para explorar las miradas de las autoras sobre el pasado y definirlas como "emprendedoras de la memoria" no sólo por el aporte de sus planteos crítico, sino también, por las características que introducen en sus poéticas. Seguimos a Jelin al definir las memorias como relatos comunicables que aportan a la construcción de sentidos del pasado y extendemos este concepto no sólo a los textos ficcionales y sus formas de representar la violencia, sino también a las narrativas críticas que contribuyen a ampliar los modos de vincular literatura e infancia desde la perspectiva de las autoras que logran capturar una parte del espíritu de la época. 
Muchas de estas narrativas surgen de los principales espacios de discusión para el campo que tienen larga trayectoria en la literatura argentina para niños, como jornadas, simposios y congresos nacionales e internacionales. En este sentido, el ejercicio crítico de este trabajo centra en la mirada en el posicionamiento de Graciela Montes como autora representativa de los principales movimientos del campo infantil argentino entre mediados de los años ochenta y los noventa, cuando se da lo que Marcela Arpes y Nora Ricaud (2008) denominan "el boom de la literatura infantil argentina". Pretendemos ampliar las fronteras del campo y para eso, seguimos los planteos de Ana Maria Machado sobre el campo infantil ya que es una de las pocas autoras brasileras con una importante producción traducida y publicada por las editoriales argentina durante los años noventa. Además, como aclaramos nos interesa reflexionar sobre los puntos de contacto y las divergencias de la experiencia de la violencia política en la literatura infantil desde la perspectiva de ambas autoras.

Un texto fundamental en este recorrido es Literatura Infantil: creación, censura y resistencia, de Montes y Machado, que reúne trabajos y conferencias expuestos en simposios y jornadas hacia fines de la década del noventa, en el marco de las políticas neoliberales que reactivaron la práctica intelectual como una práctica de resistencia cultural que ambas autoras llevaron a cabo desde las décadas anteriores y actualizaron en su discurso crítico por esos años. Por otra parte, un antecedente clave para resignificar las narrativas críticas son los textos de Walter Benjamin (1989) sobre infancia, como "Viejos libros infantiles", "Panorama del libro infantil", "Juguetes antiguos", "Historia del juguete", entre otros. Textos breves en los que se despliega la mirada del autor hacia esta zona literaria y las pasiones por la perspectiva o los intereses del niño.

En la selección de textos críticos sobre la literatura infanto-juvenil argentina estas escrituras puntuales - más que fragmentariasdesarrollan una visión crítica hacia el adulto y pertenecen mayormente a las propias autoras interesadas en problematizar esta zona literaria y difundir otras formas de participar desde la literatura en la infancia ${ }^{3}$.

\footnotetext{
${ }^{3}$ En la investigación doctoral distinguimos dos grupos de narrativas críticas, que permiten reconocer las principales problemáticas del campo infantil argentino antes y después de la dictadura. Entre las narrativas postdictatoriales se destaca la primera edición de El corral de la infancia, publicado en 1990 por Graciela Montes. Allí, la autora problematiza la mirada hacia el campo infantil con la metáfora del corral que limita los movimientos y revela las restricciones impuestas a la infancia por el mundo adulto.
} 
Entre las narrativas críticas postdictatoriales podemos incluir el texto de Montes y Machado, pero también se encuentran otros textos de la colección la llave fundamentales como Buenas palabras, malas palabras (1998) de Ana Maria Machado y La emoción más antigua: lecturas, escrituras, el encuentro con los libros (2001) de Graciela Cabal. En estos textos es posible continuar un conjunto de polémicas constitutivas del campo infantil que analizaremos en la segunda parte de este trabajo y definir un nuevo posicionamiento de las autoras que actualizan el compromiso de su práctica intelectual en el contexto democrático promoviendo la formación de lectores. Esta propuesta se desprende de la hipótesis que sostiene que el posicionamiento de un grupo de escritores de textos para niños y jóvenes en Argentina, tanto en el dominio de la ficción como en el de las polémicas que recorren el campo infantil, da cuenta de un desplazamiento hacia una literatura de "autor" donde éste es quien asume intencionalmente el desafío de ampliar la zona de lo deliberado o no para niños (Rönner, 2000).

Por lo tanto, estas narrativas críticas en el caso de la literatura argentina para niños son claves para analizar cómo se amplía el espesor (Rama, 1982) del campo desde los años sesenta en adelante y alcanza mayor visibilidad con el apoyo del mercado editorial a mediados y fines de los años ochenta a partir de la ruptura de tres planteos de larga tradición en el campo: la disminución de la mirada protectora para dirigirse al lector-niño, la superposición de modos de abordar la ficción y la complejidad de la estructura social y cultural que incluía los cambios con respecto al modelo de familia y crianza en crisis desde los años sesenta (Cosse, 2010; Carli, 1996).

El ingreso del elemento político en la ficción que cuestiona una mirada tradicional sobre la infancia y la literatura es detectado y cuestionado por el régimen militar con la prohibición de dos textos emblemáticos del campo infantil argentino como son La torre de cubos de Laura Devetach y Un elefante ocupa mucho espacio de Elsa Bornemann. Entre los argumentos de los decretos que prohíben estos textos llama la atención la crítica por exceso de fantasía y la promoción de planteos que contribuyen al adoctrinamiento del accionar subversivo y atentan contra los principios morales. Estos cuestionamientos dejan ver que el niño es entendido como un objeto capaz de ser modelado de acuerdo con los intereses del adulto - como lo demostraron las prácticas de apropiación de bebés durante la dictadura argentina -, contrariamente a los planteos 
de los nuevos modos de la ficción que le otorgan al niño el estatus de lector autónomo, con posibilidades propias para entrar y salir con libertad de los relatos literarios.

En Argentina esta ruptura, que se manifiesta con la prohibición de los textos de Devetach y Bornemann, encuentra sus principales orígenes en la obra de María Elena Walsh durante los años sesenta. La poética de Walsh promueve una literatura que subvierte el orden tradicional del mundo y se construye a partir de la lógica del absurdo y la dimensión lúdica del lenguaje, que logra desestructurar las formas tradicionales para dirigirse al niño y habilitar el ingreso de la arbitrariedad literaria en contacto con la infancia. En Brasil, esta ruptura entre la realidad y la imaginación fue planteada mucho antes por Monteiro Lobato y encuentra nuevas modulaciones en los años setenta con la propuesta estética de Ana Maria Machado, Ziraldo, Ruth Rocha, entre otros que amplían las formas de apelar a la imaginación del niño. Al respecto la autora afirma:

Por increíble que parezca, los militares no dieron la menor importancia a los libros para chicos. Tal vez, quién sabe, porque no acostumbraban leer cuentos a sus hijos, o porque no quisieron perder tiempo con esos asuntos que acaso consideraran femeninos, o quizá porque no entendían lo que decía ese lenguaje poético y simbólico. De modo que al final sucedió algo inesperado: justamente a partir del AI-5 - (conjunto de decretos de las juntas militares 1968 y 1969) - comenzó el denominado boom de la literatura infantil brasileña, con la aparición de la revista Recreio, en la que escribíamos Joel, Ruth Rocha y yo, y también con la publicación de las primeras obras de Ziraldo, Lygia Bojunga, João Carlos Marinho, Edy Lima (todas entre diciembre de 1969 y fines de 1969), así como con el nacimiento de la Fundación Nacional del Libro Infantil y Juvenil (2003, p. 114-115).

Este fragmento que pertenece a la exposición "Por una cultura de la resistencia", que Machado presenta en la $8^{\circ}$ Jornada Literaria de Passo Fundo sobre "Temas prohibidos y libros censurados en la literatura infantil", señala algunos puntos centrales para aludir a la dictadura brasilera y también, al campo de la literatura infantil que emergen con características propias en Brasil antes que en Argentina. Por un lado, la autora marca que si bien la censura apuntó a la quema de libros y la persecución de algunos autores de la literatura infantil que fueron encarcelados durante el período denominado Estado Nuevo (1937- 
1945), a diferencia de la dictadura argentina la literatura infantil brasilera no estuvo en la mira del ojo censor del último régimen (19641985) por minimizar sus alcances y repercusiones. Sus autores sufrieron el hostigamiento y el encarcelamiento por sus actividades de resistencia y militancia, pero la autora no menciona libros prohibidos, al contrario del caso argentino en el que eran conocidas las listas negras y los efectos de censura y autocensura que esto generaba (Invernizzi y Gociol, 2002).

Además, el contraste se hace evidente en el crecimiento del campo infantil brasileño y el abordaje de temas políticos, como lo expresa Machado: "no nos autocensurábamos ni evitábamos ningún tema. Hablábamos de autoritarismo, de la lucha armada, de prisiones y malos tratos, de la censura, el exilio, la discriminación, las migraciones urbanas, los chicos de la calle, las desigualdades, las injusticias y hasta la plusvalía" (2003, p. 115). Esta zona literaria no fue ajena a los problemas sociales de la época y, evidentemente, en ninguna época lo fue. Sin embargo, son pocos los estudios literarios que atienden a sus planteos porque es una zona relegada y también, tiene la marca de una zona menor ligada al ámbito femenino -como señala Machado- que vincula la literatura con el rol social de mujer-madre-maestra. En este sentido, la crítica argentina reacciona ante ese lugar pasivo asignado a la mujer en relación con la literatura y la vida social con un texto contestatario como ¿Mujercitas eran las de antes? (El sexismo en los libros para niños) (1992) de Graciela Beatriz Cabal. Otra propuesta ante esta lectura marginal para el campo es el mismo texto de Graciela Montes que denuncia la mirada del resto del sistema cultural y de la sociedad en general hacia la literatura infantil en El corral de la infancia (1990).

La disputa para desterrar la mirada tradicional e instalar una nueva mirada hacia la infancia desde la literatura por estos años y por varios actores sociales logra desligar a la literatura para niños de esa mirada de hermana "menor" un tiempo después con el posicionamiento del campo infantil argentino a través de artículo de María Adelia Díaz Rönner, "Literatura Infantil: de "menor" a mayor" (2000) del volumen 11 titulado "La narración gana la partida", incluido en la Historia crítica de la literatura argentina dirigida por Noé Jitrik. Desde nuestro punto de vista hay dos elementos destacados por Díaz Rönner que contribuyen a darle a la literatura infantil un lugar en la tardía agenda de la crítica literaria argentina: por un lado, la ruptura con el orden de tipo paternalista para concebir a los niños dado por las nuevas modulaciones 
de la ficción para apelar a la imaginación y desligarlo de la dominación que supone el didactismo en relación con la literatura a partir de los desplazamientos críticos realizados por las autoras. Por otro, la importante tradición oral que constituye el punto de partida para actualizar las formas literarias del campo desde Walsh en adelante.

Ambos elementos contribuyen a remarcar el sentido del término infantil al menos para hablar de literatura para chicos. En este punto seguimos los postulados de Jacques Derrida (1977) para entender la remarca como una operación de trasgresión por la cual al hablar de literatura "infantil" se apunta más allá del mundo de sentido que lo relacionado con lo ingenuo y lo carente de experiencia para apuntar a las posibilidades del sujeto en contacto con sus ventajas para recurrir a la imaginación. Estas posibilidades están mediadas por la figura del adulto, que en el caso de los autores del campo infantil se ocupan de desarticular el rol protector para dirigirse al niño y posicionarse con cierta horizontalidad al menos desde la propuesta estética de la literatura.

El principal movimiento del campo infantil argentino entre los sesenta y los setenta tiene que ver con una literatura de "autor" que como dijimos- se multiplica hacia fines de los años ochenta en el marco de una democracia incipiente. El desplazamiento del campo se hace evidente en la renovación de los recursos ficcionales como así también en el abordaje de nuevos temas y géneros, que comprometen también nuevos desafíos dentro del campo. Un ejemplo es el ingreso del tema de la violencia política y de ahí se desprende la pregunta sobre cómo participan los autores de la transmisión del pasado. Graciela Montes es una de las primeras autoras argentinas en abordar temas relacionados con la sociedad y junto con Laura Devetach y Graciela Beatriz Cabal forman parte de una colección dirigida a niños que trata temas relativos a las formas políticas y sociales de la ciudadanía ${ }^{4}$. En cuanto a su posicionamiento sobre el tema, la autora afirma:

Cuando volvió la democracia, y sin haber yo dejado en ningún momento mi vínculo con el Centro Editor ni con Boris Spivacow (que nunca se recuperaron del todo después de la quema - se refiere a la quema de libros en la editorial), armé el proyecto editorial de Libros del Quirquincho. Una editorial que acogiera la nueva

\footnotetext{
${ }^{4}$ Esta publicación fue reeditada y ampliada a mediados de los noventa en forma de fascículos por el diario Página/12 y el eje de las temáticas responden a preguntas como los derechos de los niños o preguntas como qué es la democracia, por qué la Argentina es una república, qué son los partidos políticos, etc.
} 
literatura para niños (una nueva palabra, una nueva mirada, que empezaba a perfilarse) y que, además, reflexionara con ellos acerca de todo lo que de veras importaba. En la entrega número 3 de la primera colección, Entender y Participar, de 1986, hablé por primera vez, de manera clara pero sencilla, como para que todos también los chicos- entendieran, de lo que había sucedido durante el terrorismo de Estado. En el '96, diez años después, me permití una reflexión más profunda en El golpe y los chicos, siempre con la idea de que los chicos, que han heredado esta historia nuestra, deben conocerla (Montes, 2003, p. 83).

Montes reconoce la continuidad del contacto entre editores y autores del campo a pesar de la violencia política, la emergencia de una nueva línea en la literatura para niños como así también, la transmisión del pasado reciente como un imperativo social en su práctica que entiende a las nuevas generaciones como herederas del pasado histórico.

Retomamos los aportes de Elizabeth Jelin para interpretar la actividad de Montes junto con la de otros autores del campo infantil que integran nuestras colecciones como "emprendedores de la memoria". Partimos de la voluntad de contar, el compromiso con la infancia y la transmisión del pasado reciente para proponer a estos autores como agentes sociales movilizados de manera colectiva con la causa de la reconstrucción del pasado y la consigna instalada por el Informe de la CONADEP en 1984 de no olvidar para que los hechos no se repitan Nunca más. Jelin (2002, p. 48) aclara: "el emprendedor se involucra personalmente en su proyecto, pero también compromete a otros, generando participación y una tarea organizada de carácter colectivo". Además, explicita que se trata de un generador de proyectos, de nuevas ideas y expresiones, de creatividad más que de repeticiones. Por eso, consideramos que la posibilidad de organizar colecciones de lecturas, en las que se rastrean nuevas formas de contar el pasado desde los parámetros de la ficción en las poéticas de los autores del campo infantil argentino contribuye no sólo a visibilizar el compromiso político de los autores con su presente, sino también aporta a la transmisión del pasado reciente.

Para concluir con este apartado nos interesa resaltar que junto con Graciela Montes y Graciela Beatriz Cabal entre otras autoras del campo argentino incluimos a Ana Maria Machado, como autoras representativas de una forma de pensar y sentir (Williams, 1980) la literatura para niños de los años noventa. Estas autoras que percibían de 
una forma particular los modos en los que la literatura participa de la infancia en las décadas anteriores advierten la importancia de la lectura y de la formación de lectores en las nuevas condiciones democráticas. Por eso, tanto sus propuestas literarias como sus prácticas intelectuales muestran que sus formas de intervenir en la sociedad en este momento están orientadas hacia una militancia por la promoción de la lectura en términos de un derecho del niño como ciudadano de un estado democrático que debe contribuir a garantizar su formación como lector.

\section{La continuidad en las polémicas del campo infantil de los años noventa}

Es importante destacar que tanto Montes como Machado señalan que una de las responsabilidades del estado democrático es intervenir desde la escuela para formar lectores e inscriben la lectura literaria como una práctica cultural constitutiva de los derechos del ciudadano. En este punto la literatura entra en la discusión con una posición social desde la que es posible repensar la infancia como un tiempo-espacio de oportunidades y el rol de las autores como militantes de la lectura literaria que basan su actividad en una serie categorías constitutiva del campo literario.

Entendemos la literatura para niños como una zona de borde disciplinar, por eso tomamos este concepto de Analía Gerbaudo (2009), quien propone explicar la relación entre literatura y enseñanza a partir de esta zona en la que confluyen los desarrollos teóricos y los posicionamientos sobre el objeto de transferencia como así también, sobre el sujeto y el contexto que irrumpe y se impone. En nuestro caso este concepto dará lugar a nuevas polémicas y categorías para analizar la lectura literaria y la literatura para niños como las causas que defienden las autoras en cuestión.

A partir del planteo de este trabajo y el estudio del campo infantil argentino es posible reconocer una tradición literaria que se manifiesta en la década del ochenta y tiene como objeto la lectura literaria en la infancia. La participación de este grupo de autores, de los cuales Montes y Machado son una parte representativa, da lugar a una línea de análisis dentro de los estudios de la crítica que entiende la lectura como una práctica social que a partir del trabajo con los protocolos de la ficción interpela los modos culturales de dirigirse a la infancia, se posiciona en 
una zona de borde en disputa con otras disciplinas como la didáctica y la psicología y, en algunos casos, se define a partir de la modalidad del taller literario como espacio de formación de lectores.

La lectura en la infancia será un tema clave en la crítica de los años dos mil en Argentina, motivado por la búsqueda de respuestas a cómo formar lectores y estimular el interés por la lectura literaria. Esto se puede rastrear en textos como La frontera indómita: en torno a la construcción y defensa del espacio poético (1999) y, más adelante, en el documento publicado por el Plan Nacional de Lectura, La gran ocasión: la escuela como sociedad de lectura (2006), ambos de Graciela Montes; en el texto antes mencionado de Graciela Cabal, La emoción más antigua: lecturas, escrituras, el encuentro con los libros (2001); en Clásicos, niños y jóvenes (2004) de Ana Maria Machado, para nombrar sólo algunos ejemplos que reúnen textos publicados a los largo de la década del noventa e incluso en la década del ochenta.

La consolidación de la literatura para niños como zona literaria está dada por la continuidad de núcleos temáticos relativos a la definición de literatura y la lectura literaria, categorías que resultan clave para actualizar las formas de escribir en la ficción y favorecer nuevos modos de leer el campo desde la crítica. Consideramos que rastrear las continuidades en las narrativas críticas del campo infantil argentino de las décadas anteriores (García, 2013b) nos permitió distinguir cómo las primeras discusiones de los años sesenta y setenta dan lugar al desplazamiento de los protocolos de la ficción, asumen nuevas modulaciones temáticas y genéricas en los años ochenta con la explosión del campo a partir del apoyo del mercado editorial y la emergencia de una nueva formación de autores de textos para chicos, quienes en los años noventa teorizan sobre la importancia de la lectura literaria y se comprometen con la formación de lectores sin renunciar a los posicionamiento de la literatura que desde el principio dan lugar a esta zona.

Tanto Graciela Montes como Ana Maria Machado se encargan de explicitar su concepción de literatura como una sola, es decir, que no distingue entre lectores niños y adultos. Por eso, confrontan con otros puntos de vista que sostienen la direccionalidad del adulto, quitándole legitimidad al niño como lector y al lenguaje literario como la posibilidad de participar de otros mundos. Con respecto a este tema Machado expone su punto de vista aludiendo a su experiencia como 
autora hacia fines de los sesenta, época en la que participaba desde el exilio en la revista Recreo de Brasil, y lo hace en los siguientes términos:

Sólo me ocupo de la literatura, de los textos que tratan las cuestiones fundamentales de la condición humana, que no intentan dar respuestas, sino que proponen, por el contrario, nuevas indagaciones sobre la experiencia humana. Libros que utilizan el lenguaje de manera poética, explorando su ambigüedad y su complejidad, proponiendo una pluralidad de significados. Textos que pueden ser leídos por los adultos con un intenso placer, pero que también pueden ser leídos y comprendidos a un nivel superficial por los niños (Machado, 2003, p. 74).

En la última parte del fragmento anterior la autora expone los argumentos que resaltan las posibilidades del niño por encima del adulto. Se trata de posicionarse ante la infancia con la complicidad de la literatura que al decir de Graciela Cabal (1992, p. 74) siempre es una invitación a saltar al vacío, una experiencia que se caracteriza por el riesgo y la incertidumbre. Este planteo se opone a la literatura hegemónica reducida a la relación de poder ejercida por el adulto que busca controlar al lector mientras simula protegerlo. Por su parte Montes logra expresar claramente esta disputa al hacer hincapié en el sentido del adjetivo calificativo que se usa para limitar los alcances de esta zona literaria y advierte:

"Lo infantil", la instalación de "lo infantil", es una forma de control social. Hay convenciones, tradiciones, maneras que se consideran propias al vínculo que entabla el adulto con el niño. Y eso actúa a la manera de un filtro, se interpone entre, por ejemplo, el que escribe para niños y su escritura. Cuanto más consciente sea el escritor de esa mediación/interferencia, más posibilidades podrá tener de quebrar los límites impuestos. "Lo infantil" es una construcción que se interpone (Montes, 2003, p. 90-91).

En esta dirección Montes muestra que se trata de uno de los pocos casos en los que el adjetivo no disminuye el sentido del sustantivo, sino lo amplía, lo alarga y afirma: "literatura infantil debería ser, sería, en rigor, aquella literatura que incluye a los niños y no la que excluye a los adultos" (Montes, 2003, p. 91). Por muchos años el aparato crítico - al menos en Argentina - contribuyó a resaltar esta cuestión de poder y los autores del campo se ocuparon de desbaratar las limitaciones de este planteo por medio de sus producciones ficcionales y la originalidad de 
sus modos de entender el campo como lo demuestra Montes. Además, esta mirada no sólo relegaba a la literatura infantil a los márgenes sino también ponía de manifiesto las miradas minimizadoras del sistema cultural hacia la infancia.

Una buena parte del planteo que asumen las autoras en los años noventa entra en disputa con el mercado editorial que toma al niño como objeto de consumo y deja de lado la auténtica apuesta de la literatura para proponer nuevos temas que responden más a fines comerciales más que a fines culturales. Así como Montes describe el papel social del trabajo intelectual del escritor que atravesó al grupo de autores argentinos en la segunda mitad de los ochenta, Machado muestra que en los años noventa cierta parte de la literatura para niños reacciona y resiste culturalmente el rechazo de los estereotipos para apostar una vez más a constituir el placer desde la invención y el esfuerzo por el desciframiento. Es importante tener en cuenta esta nueva forma de dominación que excluye la publicación de determinados textos e impone nuevos criterios en la selección:

En la literatura infantil, las presiones del mercado sobre los medios, además de prácticamente acabar con la crítica en el sector y de imponer personajes masificados provenientes de otras culturas, intentan sofocar la pujanza de nuestra creatividad por medio de una infiltración en las listas de libros vendidos. En general estas listas se confeccionaban mediante consultas a librerías especializadas o instituciones del área, pero ahora se fusionan con las de las librerías generales (Montes, 2003, p. 118).

En este entramado donde las nuevas reglas de producción y circulación parecen estar impuestas por el mercado editorial tiene lugar otra de las polémicas que atraviesa a la literatura para niños. Entendemos que la divulgación es una actividad clave para suscitar nuevas prácticas y despertar la curiosidad del público general. En el caso de la literatura infantil esta actividad toma forma en la difusión y formación de lectores dentro del contexto democrático. Por eso, entre las principales actividades de estas autoras reconocemos su participación en propuestas culturales que llevan a la literatura y a los escritores a las escuelas. Al respecto, Montes rescata su experiencia en ese contexto:

Hubo un grupo de escritores para niños que sintió en ese momento, en especial en la segunda mitad de la década del '80, cuando se reconstruía esforzadamente la democracia, que tenía 
un papel que desempeñar. Pienso en Roldán, Devetach, Cabal, Wolf, Mariño, Schujer...Se multiplicaron los lazos con maestros y bibliotecarios, se tomó parte muy activa en un Plan Nacional de Lectura que activó las alicaídas pero muy tradicionales bibliotecas populares y se reflexionó mucho en torno del papel de la lectura en la sociedad y la literatura infantil. A esos años se remite la fundación de A.L.I.J.A., la sede nacional del I.B.B.Y. y el grupo cordobés C.E.D.I.L.I.J., y los albores de una reflexión universitaria (seminarios, el CeProPalij, de la Universidad del Comahue) (Montes, 2003, p. 83).

En este sentido, los autores asumen un compromiso con la difusión y la escuela se presenta como la oportunidad de democratizar la lectura literaria y romper de una vez con la literatura como una cuestión de elites sociales. Al menos hacia fines de los ochenta en Argentina, Montes recuerda con éxito esa "instalación social" de la literatura infantil que se debió entre otros factores a la aparición de un nuevo actor social, que ella denominó el lector-mediador, a quien define en los siguientes términos: "bibliotecarios, maestros, padres, libreros -todos buenos lectores- que asumieron la defensa de esta nueva instancia literaria no de manera institucional sino como algo propio" (Montes, 2003, p. 69).

Por el contario, en los años noventa el ingreso de la literatura a las escuelas se relaciona con la responsabilidad del estado en la formación del niño como lector y ese planteo pone de manifiesto nuevas dificultades. Por un lado, se reactivan la disputa entre literatura y enseñanza y, por otro, se evidencia la complejidad del tema ya que no sólo implica concebir al niño, sino también al docente como lector. Con respecto a este punto la perspicacia de autoras como Graciela Cabal para resaltar la importancia del docente como mediador es fundamental: "La eficacia del maestro como mediador tiene que ver con que el maestro sea lector o no lo sea" (Cabal, 2001, p. 74). En esta dirección entre los criterios del mercado, su propósitos comerciales y la falta de auténticos mediadores, la literatura corre el riesgo de ser escolarizada, es decir, de ser utilizada con propósitos didácticos y, aún más, perderse en la dicotomía de la cultura creativa o la cultura de masa, que expresa claramente Machado (2003, p. 121): "la literatura por hacer un uso estético de la palabra, experimenta con lo que aún no se ha dicho, inventa algo nuevo, propone prototipos, mientras que los textos de la cultura de masas 
vienen cargados de estereotipos, trayendo sólo redundancia y repetición de lo ya existente, consolidación del status quo".

La significación social de la lectura en un contexto de carencias materiales es fundamentan para interpelar al estado desde el posicionamiento de nuestras autoras. En una exposición de 1998, titulada "El espacio social de la lectura", Montes trata de mostrar cómo la percepción de la lectura encierra una disputa entre lo que se espera y lo que se mantiene de acuerdo con los cambios en las condiciones sociales y culturales y afirma:

Leer parece suponer siempre encontrar una clave, una llave. Interpretar señales. Perseguir el sentido. Ver el otro lado de las cosas. Hurgar y ahondar. Explayarse. Criticar. Y tejer: construir un relato. Sólo que lo que hoy no parece ser la crítica ni la argumentación ni el razonamiento ni la narración - me refiero siempre a nuestra estructura de sentimento - sino más bien el consumo, lo fugaz, la acumulación destejida, lo fragmentario, el espectáculo (Montes, 2003, p. 30).

Este cambio pone el acento en la importancia cultural de la lectura que no puede dejarse librada al azar, por eso las autoras insisten en la presencia del estado como garante de esta práctica. Pero no se trata de multiplicar el consumo de literatura sino de asegurar el encuentro con la literatura y de comprometerse con una auténtica experiencia que incluya cada vez más una mayor cantidad de lectores. En este sentido la propuesta de nuestras autoras desde sus diferentes experiencias y sus intereses compartidos apunta en la misma dirección. Una buena síntesis de los argumentos que sustentan su práctica intelectual esté en estas palabras de Ana Maria Machado (2003, p. 18):

Todo ciudadano tiene derecho a poder acceder a la literatura y descubrir y compartir una herencia humana común. El placer de leer no significa solamente encontrar divertida una historia o seguir las peripecias de una trama atractiva y fácil; además de los placeres sensoriales que compartimos con otras especies, existe un placer puramente humano: el de pensar, descifrar, argumentar, razonar, cuestionar, en fin, unir y confrontar ideas diversas. Y la literatura es una de las mejores maneras de encaminarnos hacia ese territorio de refinados placeres. Una democracia no es digna de tal nombre si no logra proporcionar a todos el acceso a la lectura de literatura. 
Por último, en el marco de los actuales estudios de infancia que apuntan a considerar las múltiples infancias y cuentan con los marcos legales necesarios para entender a los niños, niñas y adolescente como sujeto de derecho es necesario revisar los argumentos de estas autoras e interpelar la aplicación de los derechos culturales de nuestros estados. A partir de los postulados de Graciela Montes y Ana Maria Machado y en consonancia con las políticas públicas implementadas en Argentina y Brasil en la última década, nos proponemos llevar las discusiones más allá y en vistas de la importancia de la lectura literaria y las oportunidades de participar de otros mundos que nos presenta la literatura nos preguntamos si no es posible incluir dentro de los derechos culturales el derecho a la imaginación para revisar desde allí la eficacia de las prácticas literarias actuales.

\section{Referências}

ARPES, Marcela; RICAUD, Nora (2008), Literatura infantil argentina: infancia, política y mercado en la construcción de un género masivo Buenos Aires: La Crujía.

BENJAMIN, Walter (1989). Escritos: la literatura infantil, los niños y los jóvenes. Buenos Aires: Nueva Visión.

CABAL, Graciela (1992). Mujercitas ieran las de antes? (El sexismo en los libros para chicos). Buenos Aires: Libros Del Quirquincho.

CABAL, Graciela (2001) La emoción más antigua: lecturas, escrituras, el encuentro con los libros. Buenos Aires: Sudamericana.

CARLI, Sandra (1996). Infancia, psicoanálisis y crisis de generaciones: una exploración de las nuevas formas del debate en educación (1955-1983). In: PUIGGRÓS, Adriana (Dir.). Dictaduras y utopías en la historia reciente de la educación argentina (1955-1983) historia de la Educación en la Argentina VIII. Buenos Aires: Galerna. p. 221-287.

CONADEP (1984). Nunca más: informe de la Comisión Nacional sobre la Desaparición de personas. Buenos Aires: EUDEBA.

COSSE, Isabella (2010). Pareja, sexualidad y familia en los años sesenta: una revolución discreta en Buenos Aires. Buenos Aires: Siglo XXI.

DERRIDA, Jacques (1977). Posiciones: entrevistas con Henri Ronse, Julia Kristeva, Jean-Louis Houdebine y Guy Scarpetta. Traducción de Manuel Arranz. Valencia: Pre-Textos. 
GARCÍA, Laura R. (2013a). Lo monstruoso en la literatura argentina para niños. Colección de lecturas para contar la violencia política. Telar. Revista del Instituto Interdisciplinario de Estudios Latinoamericanos, Tucumán, n. 12. (en prensa).

GARCÍA, Laura R. (2013b). El posicionamiento de la narrativa crítica en la literatura argentina para niños 1970-1990). In: JORNADAS DE POÉTICAS DE LA LITERATURA ARGENTINA PARA NIÑOS, 5., La Plata, 13 y 14 de septiembre de 2013. Actas... La Plata: FaHCE. Disponible en: <http://jornadasplan.fahce.unlp.edu.ar/v-jornadas-2013/ponencias/a19.pdf >.

GERBAUDO, Analía (2007). Derrida y la construcción de un nuevo canon crítico para las obras literarias. Córdoba: Universitaslibros; Ed. FFyH (UNC).

GERBAUDO, Analía (2009). Literatura y enseñanza. In: DALMARONI, Miguel (Dir.). La investigación literaria: problemas iniciales de una práctica. Santa Fe: Ediciones UNL. p. 165-194.

INVERNIZZI, Hernán; GOCIOL, Judith (2002). Un golpe a los libros. Represión a la cultura durante la última dictadura militar. Buenos Aires: Eudeba.

JACKSON, Rosmary (1986). Fantasy: literatura y subversión. Buenos Aires: Catálogos.

JELIN, Elizabeth (2002). Los trabajos de la memoria, memorias de la represión. Buenos Aires: Siglo XXI.

MACHADO, Ana Maria; MONTES, Graciela (2003). Literatura infantil: creación, censura y resistencia. Buenos Aires: Sudamericana.

MACHADO, Ana Maria (2004). Clásicos, niños y jóvenes. Traducción de Santiago Ochoa. Bogotá: Norma.

MONTES, Graciela (1996). El golpe y los chicos. Buenos Aires: Gramón-Colihue Libros.

MONTES, Graciela (1991/2007). Otroso: últimas noticias del mundo Subterráneo. Buenos Aires: Alfaguara.

NOFAL, Rossana (2006). Literatura para chicos y memorias: colección de lecturas. In: JELIN, Elizabeh; KAUFMAN, Susana (Comp.). Subjetividad y figuras de la memoria. Buenos Aires: Siglo Veintiuno p. 111- 129.

RAMA, Angel (1982). El espesor de la literatura. In: RAMA, Angel. Los gauchipolíticos rioplatenses: literatura y sociedad. Buenos Aires: CEAL. p. 16-23.

RÖNNER, María Adelia Díaz (2000). Literatura infantil de "menor" a "mayor". In: JITRIK, Noé (Dir.). Historia crítica de la literatura argentina. Tomo 11. Buenos Aires: Emecé. p. 511- 531.

WILLIAMS, Raymond (1980). Marxismo y literatura. Barcelona: Península. 
Recebido em novembro de 2014.

Aprovado em março de 2015.

\section{resumo/abstract}

\section{Narrativas del pasado y literatura infantil: continuidades y rupturas en los planteos críticos de Graciela Montes y Ana Maria Machado}

\section{Laura Rafaela García}

Este trabajo propone continuar los estudios iniciados en otras instancias de investigación con el fin de explorar la literatura infanto-juvenil desde los estudios literarios y el impacto de la violencia política de las últimas dictaduras militares. El texto recorrerá las miradas del pasado a partir de la experiencia de dos autoras claves para la literatura infantil de Argentina y de Brasil, como son Graciela Montes y Ana Maria Machado. Por un lado, este estudio pretende profundizar en los modos en los que la violencia política de la última dictadura incidió en las prácticas intelectuales de estas autoras en los dos países. Esto nos permitirá establecer similitudes y diferencias entre ambos casos. Por otro lado, avanzaremos en el análisis de narrativas críticas entendidas como memorias fundamentales para la reconstrucción de las polémicas que definieron los principales planteos de la literatura para niños en los años noventa, dentro del contexto democrático. El posicionamiento crítico de las autoras con respecto a los movimientos de su campo y las características del contexto de cada país contribuye a profundizar en los modos desde los cuales la literatura participa de la infancia.

Palavras-chave: literatura infantil argentina, literatura infantil brasilera, Graciela Montes, Ana Maria Machado.

\section{Narratives of the past and children's literature: continuities and discontinuities in critical proposals of Graciela Montes and Ana Maria Machado}

\section{Laura Rafaela García}

This paper proposes to continue the studies initiated in other instances of research to explore the children's literature from literary studies and the impact of political violence in recent military dictatorships. The text looks last tour from the experience of two key authors of children's literature for Argentina and Brazil, such as Graciela Montes and Ana Maria Machado. First, this study aims to deepen the ways in which the political violence of the dictatorship fell upon the intellectual authors of these practices in the two countries. This will allow us 
to establish similarities and differences between the two cases. On the other hand, advance in the analysis of narrative reviews understood as fundamental memories for the reconstruction of the controversies that defined the main proposals of children's literature in the nineties, in a democratic context. The critical position of the authors regarding the movements of their field and the characteristics of the context of each country contributes to deeper modes from which literature participates childhood.

Keywords: Argentina children's literature, Brazilian children's literature, Graciela Montes, Ana Maria Machado. 